\title{
PEMANFAATAN ABU KERTAS DAN SERBUK CANGKANG LOKAN PADA CAMPURAN BETON NORMAL DENGAN MENGGUNAKAN SIKACIM CONCRETE ADDITIVE
}

\author{
MULYATI, WIKI YULANDI \\ Institut Teknologi Padang \\ mulyati_tsp@yahoo.com
}

\begin{abstract}
This research uses paper ash, lokan shell powder, and sikacim concrete additive for normal concrete mix. Paper ash is used as a cement additive, while lokan shell powder is used as a partial substitute for sand. To overcome the lack of water in the concrete mixture, Sikacim concrete additive is used. The purpose of this study was to determine the compressive strength of concrete resulting from the use of paper ash as an additive and lokan shell powder as a substitute for sand by adding sikacim concrete additive. The test object used a cube mold of $15 \mathrm{~cm} \times 15 \mathrm{~cm} \times 15 \mathrm{~cm}$ with a concrete compressive strength of K-250 design at the age of 28 days of testing. Variations of the specimens used paper ash $0.25 \%$ by weight of cement, and lokan shell powder 0\%,10\%, 20\%, 30\% by weight of sand, and 0.7\% additive from the volume of water. Based on the results of the compressive strength test of concrete, the compressive strength of concrete is obtained, for normal concrete it is $276.6 \mathrm{~kg} / \mathrm{cm}^{2}$, from the use of $0.25 \%$ paper ash, $0 \%$ lokan shell and $0.7 \%$ additive of $362.6 \mathrm{~kg} / \mathrm{cm}^{2}$, from the use of $0.25 \%$ paper ash, $10 \%$ lokan shell and $0.7 \%$ additive of $365.3 \mathrm{~kg} / \mathrm{cm}^{2}$, from the use of $0.25 \%$ paper ash, 20\% lokan shell and $0.7 \%$ additive of $300.53 \mathrm{~kg}$ $/ \mathrm{cm}^{2}$, from the use of $0.25 \%$ paper ash, 30\% lokan shell and $0.7 \%$ additive of 250.16 $\mathrm{kg} / \mathrm{cm}^{2}$.
\end{abstract}

Keywords: paper ash, lokan shell powder, sikacim concrete additive, normal concrete

\begin{abstract}
Abstrak: Penelitian ini menggunakan abu kertas, serbuk cangkang lokan, dan sikacim concrete additive untuk campuran beton normal. Abu kertas digunakan sebagai bahan tambah semen, sedangkan serbuk cangkang lokan digunakan sebagai pengganti sebagian pasir. Untuk mengatasi kekurangan air pada campuran beton digunakan zat additive sikacim concrete additive. Tujuan penelitian ini adalah untuk mengetahui kuat tekan beton yang dihasilkan dari penggunaan abu kertas sebagai bahan tambah dan serbuk cangkang lokan sebagai pengganti pasir dengan menambahkan zat additive sikacim concrete additive. Benda uji menggunakan cetakan kubus $15 \mathrm{~cm}$ x $15 \mathrm{~cm}$ x $15 \mathrm{~cm}$ dengan kuat tekan beton rencana K-250 pada umur pengujian 28 hari. Variasi benda uji menggunakan abu kertas $0,25 \%$ dari berat semen, dan serbuk cangkang lokan $0 \%$, $10 \%, 20 \%, 30 \%$ dari berat pasir, serta additive 0,7\% dari volume air. Berdasarkan hasil uji kuat tekan beton didapatkan kuat tekan beton, untuk beton normal sebesar 276,6 $\mathrm{kg} / \mathrm{cm}^{2}$, dari penggunaan $0,25 \%$ abu kertas, cangkang lokan $0 \%$ dan additive $0,7 \%$ sebesar $362,6 \mathrm{~kg} / \mathrm{cm}^{2}$, dari penggunaan $0,25 \%$ abu kertas, cangkang lokan $10 \%$ dan additive $0,7 \%$ sebesar $365,3 \mathrm{~kg} / \mathrm{cm}^{2}$, dari penggunaan $0,25 \%$ abu kertas, cangkang lokan $20 \%$ dan additive $0,7 \%$ sebesar $300,53 \mathrm{~kg} / \mathrm{cm}^{2}$, dari penggunaan $0,25 \%$ abu kertas, cangkang lokan $30 \%$ dan additive $0,7 \%$ sebesar $250,16 \mathrm{~kg} / \mathrm{cm}^{2}$.
\end{abstract}

Kata kunci: abu kertas, serbuk cangkang lokan, sikacim concrete additive, beton normal 


\section{A. Pendahuluan}

Pada dasarnya dalam membuat campuran beton yang menjadi tuntutan utama adalah mengenai kekuatan tekan beton. Untuk meningkatkan kekuatan tekan beton, ada beberapa cara yang dapat dilakukan, diantaranya dengan memberikan bahan tambah pada campuran beton yang diharapkan dapat meningkatkan sifat mekanis beton yaitu kuat tekan. Menurut Nugraha (2007), bahan tambah digunakan untuk memperbaiki performa beton terutama kekuatannya, bahan tambah yang digunakan berupa bahan alami maupun kimia, bahan tambah yang bersifat pozzolanik dapat meningkatkan performa kekuatan beton.

Menurut Norman dan Juis (2009), kertas adalah bahan yang tipis, yang dihasilkan dengan kompresi serat yang berasal dari pulp. Serat yang digunakan biasanya adalah alami dan mengandung silikon dioksida ( $\mathrm{SiO})$, Aluminium Oksida (AI2O3), Magnesium Oksida $(\mathrm{MgO})$, Kalsium Oksida $(\mathrm{CaO})$ serta Ferri Oksida (Fe2O3). Senyawa dalam kertas memiliki senyawa kalsium yang sama dengan unsur senyawa dalam semen, oleh karenanya kertas yang dibakar menjadi abu bisa dijadikan sebagai bahan penambah untuk semen. Mulyati dan Arafan (2019) melakukan penelitian menggunakan abu kertas sebagai bahan tambah campuran beton dengan variasi abu kertas $0 \%, 0,25 \%, 0,5 \%, 0,75 \%, 1 \%$ dari berat semen, dan menambah sikacim concrete additive masing-masing 0,7\% dari volume air. Dari hasil pengujian kuat tekan beton, diperoleh kuat tekan tertinggi pada penggunaan abu kertas $0,25 \%$ dan sikacim $0,7 \%$ dengan nilai kuat tekan rata-rata $295,14 \mathrm{~kg} / \mathrm{cm}^{2}$.

Salah satu bahan utama untuk pembuatan beton adalah agregat halus, yang ketersediaannya di alam terbatas. Ada beberapa limbah yang dapat digunakan sebagai pengganti pasir, seperti lokan. Lokan merupakan salah satu komoditi laut yang banyak dimanfaatkan dalam kegiatan sehari-hari. Sebagian besar pemanfaatnnya belum dilakukan secara maksimal hanya terbatas pada dagingnya saja untuk konsumsi. Pemanfaatan kulit lokan sebagai bahan campuran pada beton masih belum banyak dilakukan. Menurut Wahju (2004) cangkang kerang mengandung kalsium sebesar $37 \%$ - 39\%, selain itu cangkang kerang mengandung $\mathrm{SiO}^{4}$ sekitar 0,82\%. Erfina (2009) juga melakukan penelitian terhadap cangkang kerang mendapatkan hasil bahwa pada cangkang kerang mengandung zat kalsium oksida $(\mathrm{CaO})$ sebanyak $53,03 \%$, dengan kandungan kalsium yang tinggi pada cangkang kerang tersebut limbah cangkang kerang diharapkan dapat digunakan sebagai bahan tambah agregat halus untuk meningkatkan kekuatan awal beton. Penyerapan air oleh cangkang lokan menyebabkan kadar air pada adukan berkurang, karena semakin sedikit air maka beton akan semakin cepat mengeras, namun beton masih diharapkan workabality. Czernin (1980) dalam Wahyuni, dkk (2013) menyatakan bahwa cangkang lokan mengandung $\mathrm{CaCO} 3$ yang jika dipanaskan akan menjadi $\mathrm{CaO}$ dan melepaskan $\mathrm{CO} 2$ ke udara. $\mathrm{CaO}$ dan $\mathrm{Si}$ adalah bahan utama pembuat semen selain $\mathrm{Fe} 2 \mathrm{O} 3$ dan $\mathrm{Al}$. Mulyati (2014), melakukan penelitian menggunakan serbuk cangkang lokan sebagai pengganti agregat halus untuk campuran beton normal dengan variasi $10 \%$, $20 \%$, dan 30\% dari berat pasir. Dari hasil pengujian kuat tekan beton diperoleh kuat tekan tertinggi pada penggunaan 30\% serbuk cangkang lokan, yaitu sebesar 266,5 $\mathrm{kg} / \mathrm{cm}^{2}$. Penggunaan serbuk cangkang lokan dapat meningkatkan kuat tekan beton sampai $6,3 \%$ dari kuat tekan beton normal.

Sikacim concrete additive adalah salah satu jenis additive yang dapat digunakan untuk pembuatan beton. Sikacim concrete additive sebagai campuran adukan beton berfungsi mempercepat pengerasan beton. Zat additive jenis ini mempunyai keunggulan, yaitu dapat mengurangi pemakaian air sampai 15\%, disamping itu juga 
dapat mempermudah pengecoran, serta mengurangi keropos pada beton (PT. Sika Indonesia). Berdasarkan penelitian Jamal, dkk (2017) yang menggunakan additive pada campuran beton didapatkan kuat tekan beton tertinggi dari penggunaan sikacim concrete additive $0,7 \%$ dari berat semen.

Pada penelitian ini abu kertas digunakan sebagai bahan tambah semen, dan serbuk cangkang lokan sebagai pengganti sebagian pasir, untuk mengatasi kekurangan air pada campuran beton digunakan sikacim concrete additive, yang perlu dikaji lebih lanjut dengan melakukan eksperimen di laboratorium. Dengan demikian dapat diketahui kuat tekan beton yang dihasilkan dari kombinasi menggunakan abu kertas, serbuk cangkang lokan, dan sikacim concrete additive.

\section{B. Metodologi Penelitian}

Penelitian ini bersifat ekperimen yang dilakukan di Laboratorium Teknik Sipil Institut Teknologi Padang. Adapun bagan alir penelitian diperlihatkan pada Gambar 1.

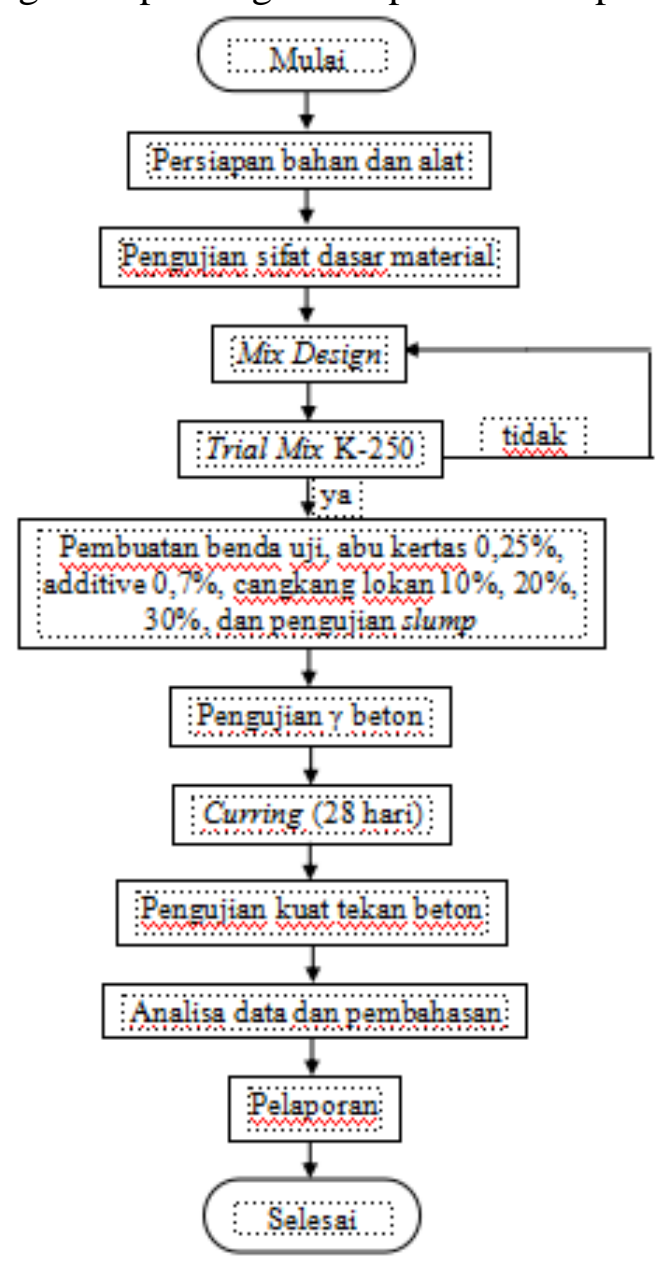

Gambar 1. Bagan Alir Pelaksanaan Penelitian

Pada penelitian ini bahan dasar penyusun beton yang digunakan adalah agregat kasar berupa koral dari Sungai Batang Kuranji, agregat halus berupa pasir dari Sungai Gunung Nago, Semen Porland Composite Cement produksi PT. Semen Padang, serta menggunakan bahan tambah berupa abu kertas, serbuk cangkang lokan, dan sikacim concrete additive, sebagaimana diperlihatkan pada Gambar 2, Gambar 3, dan Gambar 4. 


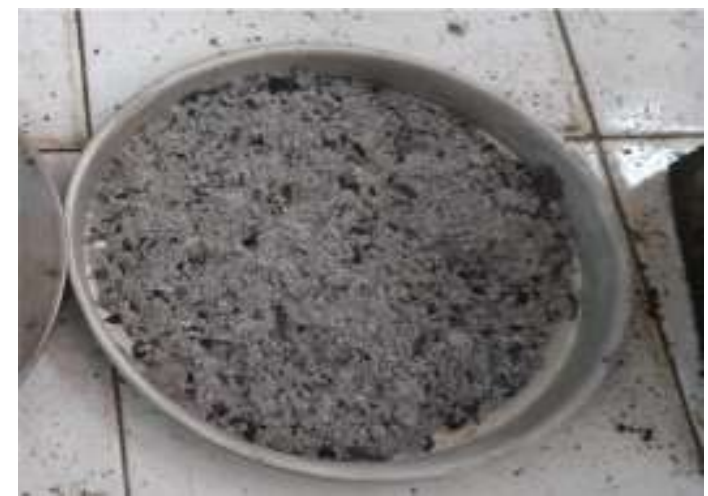

Gambar 2. Abu Kertas

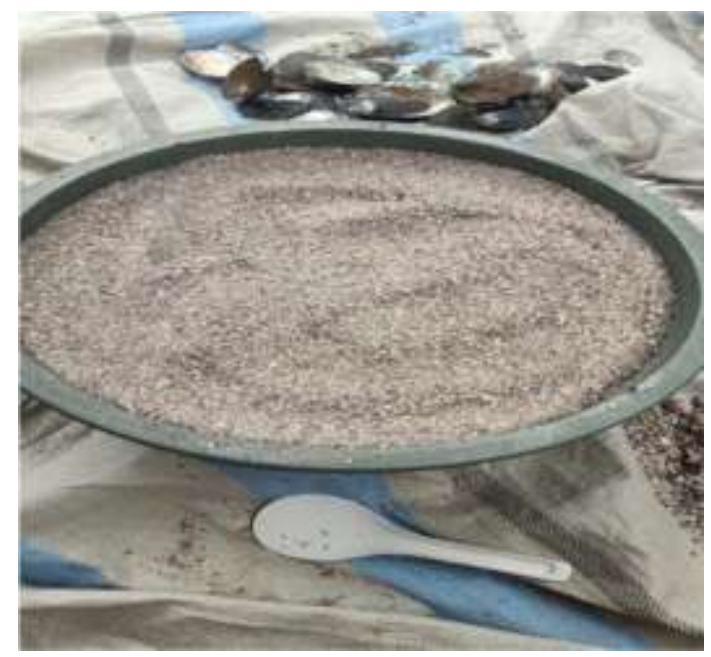

Gambar 3. Serbuk Cangkang Lokan

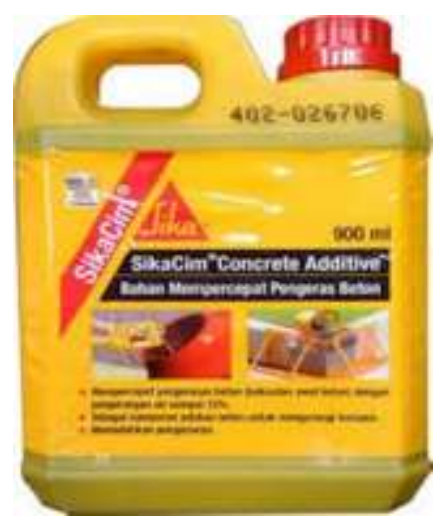

\section{Gambar 4. Sikacim Concrete Additive}

Peralatan untuk pengolahan kertas digunakan tungku pembakaran, serta alat-alat untuk pengujian agregat kasar dan agregat halus terdiri dari; timbangan, saringan untuk pengujian gradasi, oven, talam logam, mesin penggetar saringan (sieve shaker), kuas, sikat kuningan, sendok, gelas ukur berisi larutan NAOH 3\%, standar warna (organic plat), silinder, tongkat pemadat, mistar baja, handuk, mesin penggetar (vibrator), kompor listrik, keranjang besi beserta alat penggantung, bak perendam, kerucut terpancung, labu takar (piknometer), jam/stopwatch, dan mesin abrasi Los Angeles. Alat-alat pembuatan benda uji terdiri dari; sekop, ember, timbangan, gelas ukur, mixer $/$ molen, sendok semen, dan cetakan kubus $15 \mathrm{~cm}$ x $15 \mathrm{~cm}$ x $15 \mathrm{~cm}$. Alat pengujian slump berupa kerucut abrams, dan tongkat pemadat, stopwatch, mistar. Alat pengujian 
kuat tekan beton berupa Universal Testing Machine (UTM) jenis Compression Testing Mchine dengan kapasitas $2000 \mathrm{kN}$ merek Controls.

Pemeriksaan material dilakukan terhadap agregat kasar (koral), agregat halus (pasir), abu kertas, dan serbuk cangkang lokan. Pada agregat kasar dilakukan pemeriksaan gradasi, pemeriksaan bahan yang terdapat dalam agregat kasar yang lolos saringan no.200, pemeriksaan berat isi, pemeriksaan berat jenis dan penyerapan, dan pemeriksaan keausan. Pada agregat halus dilakukan pemeriksaan gradasi, pemeriksaan kadar zat organik, pemeriksaan bahan yang terdapat dalam agregat halus yang lolos saringan no.200, pemeriksaan berat isi, pemeriksaan berat jenis dan penyerapan. Pada abu kertas dilakukan pemeriksaan analisa saringan lolos saringan no.200, sedangkan serbuk cangkan lokan lolos saringan no.4, serta pemeriksaan berat jenis.

Dari hasil pemeriksaan sifat dasar material pembentuk beton, dihitung perencanaan campuran beton (mix design) menggunakan metode SK SNI T-15-199003 tentang Tata Cara Rencana Pembuatan Campuran Beton Normal, untuk kuat tekan rencana $\mathrm{K}_{250}$ pada umur 28 hari dengan faktor air semen 0,5 diperoleh kebutuhan material campuran beton dalam satuan berat untuk $1 \mathrm{~m}^{3}$ beton diperlihatkan dalam Tabel 1, dan untuk 3 benda uji diperlihatkan dalam Tabel 2.

Tabel 1 Kebutuhan Material Campuran Beton Untuk $1 \mathrm{~m}^{3}$ Beton

\begin{tabular}{ccc}
\hline No & Jenis Material & Kebutuhan \\
\hline 1. & Semen & $317 \mathrm{~kg}$ \\
2. & Air & $190 \mathrm{liter}$ \\
3. & Pasir & $685,1 \mathrm{~kg}$ \\
4. & & \\
& Koral & $1217,9 \mathrm{~kg}$ \\
\hline Tabel 2 Kebutuhan Material Campuran Beton Untuk 3 Benda Uji \\
\hline No & Jenis Material & Kebutuhan \\
\hline 1. & Semen & $3,2 \mathrm{~kg}$ \\
2. & Air & 1,96 liter \\
3. & Pasir & $6,6 \mathrm{~kg}$ \\
4. & & $12 \mathrm{~kg}$ \\
\hline
\end{tabular}

Untuk membuktikan tercapainya kuat tekan beton rencana dilakukan trial mix sesuai komposisi rancangan beton untuk 3 kubus, dengan melakukan pengujian slump dan kuat tekan beton pada umur 3 hari. Campuran beton dengan bahan tambah, setiap variasi 3 benda uji dibutuhkan abu kertas dari berat semen untuk berat jenis abu kertas $0,5 \mathrm{gr} / \mathrm{cm}^{3}$, dan dibutuhkan serbuk cangkang lokan dari berat pasir untuk berat jenis serbuk cangkang lokan $2,3 \mathrm{gr} / \mathrm{cm}^{3}$, serta dibutuhkan sikacim concrete additive dari volume air untuk berat jenis sikacim concrete additive $1,2 \mathrm{gr} / \mathrm{cm}^{3}$, diperlihatkan dalam Tabel 3.

Tabel 3 Kebutuhan Abu Kertas, Serbuk Cangkang Lokan, dan Sikacim Concrete Additive,

\begin{tabular}{cccc}
\hline Variasi & Abu Kertas & Serbuk Cangkang Lokan & Sikacim Concrete Additive \\
\hline 1 & $0 \%$ & $0 \%$ & $0 \%$ \\
2 & $0,25 \%=0,008 \mathrm{gr}$ & $0 \%$ & $0,7 \%=11,67 \mathrm{ml}$ \\
3 & $0,25 \%=0,008 \mathrm{gr}$ & $10 \%=0,29 \mathrm{gr}$ & $0,7 \%=11,67 \mathrm{ml}$ \\
4 & $0,25 \%=0,008 \mathrm{gr}$ & $20 \%=0,57 \mathrm{gr}$ & $0,7 \%=11,67 \mathrm{ml}$ \\
& & & \\
5 & $0,25 \%=0,008 \mathrm{gr}$ & $30 \%=0,86 \mathrm{gr}$ & $0,7 \%=11,67 \mathrm{ml}$ \\
\hline
\end{tabular}


Pembuatan benda uji dengan menggunakan cetakan kubus $15 \mathrm{~cm} \times 15 \mathrm{~cm} \times 15 \mathrm{~cm}$, untuk variasi campuran dengan menggunakan bahan tambah abu kertas 0,25\% dari berat semen, additive 0,7\% dari volume air, dan serbuk cangkang lokan 0\%, 10\%, $20 \%$, dan $30 \%$ dari berat pasir Setiap variasi campuran dibuat untuk 3 benda uji, dan dilakukan pengujian slump untuk mengetahui kekentalan adukan beton dengan batasan nilai slump yang ditetapkan $3 \mathrm{~cm}-6 \mathrm{~cm}$.

Perawatan (curring) beton dilakukan dengan cara merendam benda uji di dalam bak perendaman berisi air bersih, yang dilakukan sampai umur rencana pengujian kuat tekan beton. Pengujian kuat tekan beton dilakukan setelah beton berumur 28 hari, sesuai metode pengujian SNI 03-1974-1990, dengan menggunakan Universal Testing Machine (UTM) jenis Compression Testing Mchine dengan kapasitas $2000 \mathrm{kN}$ merek Controls dengan pembebanan yang diberikan sampai benda uji runtuh yaitu pada saat beban maksimum dapat ditahan oleh benda uji. Dari hasil pengujian kuat tekan beton akan diketahui apakah abu kertas sebagai bahan tambah dan serbuk cangkang lokan sebagai pengganti sebagian pasir dapat digunakan sebagai bahan campuran beton, serta mengetahui pengaruh penambahan additive pada campuran beton tersebut.

\section{Hasil dan Pembahasan}

Hasil pemeriksaan sifat dasar material agregat kasar (koral) yang berasal dari Sungai Batang Kuranji dan agregat halus (pasir) yang berasal dari Sungai Gunung Nago ) memenuhi spesifikasi, diperlihatkan dalam Tabel 4 dan Tabel 5.

Tabel 4 Sifat Dasar Agregat Kasar (Koral) Sungai Batang Kuanji

\begin{tabular}{clcl}
\hline No & \multicolumn{1}{c}{ Jenis Pemeriksaan } & Hasil & \multicolumn{1}{c}{ Spesifikasi } \\
\hline 1. & Gradasi & Modulus kehalusan butir & Butiran mak. 40 \\
2. & Passing 200 & 6,92 & mm \\
3. & Berat isi & $0,9 \%$ & Mak. 1\% \\
4. & Berat jenis dan penyerapan & $1,44 \mathrm{gr} / \mathrm{cm}^{3}$ & Min. 1,2 gr/cm \\
& -Berat jenis apparent & 2,91 & Min. 2,3 \\
& -Berat jenis kering (dry & 2,72 & Min. 2,3 \\
& basis) & 2,78 & \\
& -Berat jenis SSD & $3,38 \%$ & Min. 2,3 \\
5. & -Penyerapan air & $23,34 \%$ & Mak. 5\% \\
6. & Keausan (abrasi) & & Mak. 27\% $-30 \%$ \\
\hline
\end{tabular}

Tabel 5 Sifat Dasar Agregat Halus (Pasir) Sungai Gunung Nago

\begin{tabular}{clcl}
\hline No & \multicolumn{1}{c}{ Jenis Pemeriksaan } & Hasil & \multicolumn{1}{c}{ Spesifikasi } \\
\hline 1. & Gradasi & $\begin{array}{c}\text { Modulus kehalusan butir } \\
\text { 3,9 (pasir kasar) }\end{array}$ & $\begin{array}{l}\text { 2,9-3,5 } \\
\text { (Pasir kasar) }\end{array}$ \\
2. & Zat organik & kadar organik warna no.2 & Mak. no.3 \\
3. & Passing 200 & $1,48 \%$ & Mak. 5\% \\
4. & Berat isi & $1,39 \mathrm{gr} / \mathrm{cm}^{3}$ & Min. 1,2 $\mathrm{gr} / \mathrm{cm}^{3}$ \\
5. & Berat jenis dan penyerapan & & \\
& -Berat jenis apparent & 2,54 & Min. 2,3 \\
& -Berat jenis kering $(d r y$ & 2,27 & Min. 2,3 \\
& basis) & & \\
& -Berat jenis SSD & 2,38 & Min. 2,3 \\
6. & -Penyerapan air & $4,71 \%$ & Mak. 5\% \\
\hline
\end{tabular}


Pengujian slump dilakukan pada setiap variasi campuran benda uji, hubungan antara variasi penambahan abu kertas, serbuk cangkang lokan, dan sikacim concrete additive, dengan nilai slump, dapat dilihat dalam Tabel 6.

Tabel 6 Nilai Slump Adukan Beton Campuran Abu Kertas, Serbuk Cangkang Lokan, dan Additive

\begin{tabular}{|c|l|c|}
\hline No & \multicolumn{1}{|c|}{ Variasi } & Nilai slump $(\mathrm{cm})$ \\
\hline 1 & Beton normal & 4,2 \\
\hline 2 & $0,25 \%$ abu kertas, 0\% serbuk cangkang lokan, 0,7\% additive & 5,2 \\
& \multicolumn{1}{|c|}{ cangkang lokan. } & 5,4 \\
\hline 3 & $0,25 \%$ abu kertas, 10\% serbuk cangkang lokan, 0,7\% additive & \\
\hline 4 & $0,25 \%$ abu kertas, 20\% serbuk cangkang lokan, 0,7\% additive & 5,7 \\
\hline 5 & $0,25 \%$ abu kertas, 30\% serbuk cangkang lokan, 0,7\% additive & 5,8 \\
\hline
\end{tabular}

Dari hasil pengujian slump pada setiap variasi campuran menunjukkan bahwa nilai slump yang didapat memenuhi batasan nilai slump adukan beton yang ditetapkan $3 \mathrm{~cm}-6 \mathrm{~cm}$. Hasil pengujian kuat tekan beton umur 28 hari untuk setiap variasi campuran benda uji, dapat dilihat dalam Tabel 7. Hubungan antara variasi abu kertas, serbuk cangkang lokan, dan sikacim concrete additive diperlihatkan pada Gambar 5.

Tabel 7 Hasil Pengujian Kuat Tekan Beton Campuran Abu Kertas, Serbuk Cangkang Lokan, dan Additive

\begin{tabular}{lccccc}
\hline \multicolumn{1}{c}{ Variasi } & $\begin{array}{c}\text { Nomor } \\
\text { Benda } \\
\text { Uji }\end{array}$ & $\begin{array}{c}\text { Berat } \\
(\mathbf{k g})\end{array}$ & $\begin{array}{c}\text { Tekanan } \\
(\mathbf{k g})\end{array}$ & $\begin{array}{c}\text { Kuat } \\
\text { Tekan } \\
\left(\mathbf{k g} / \mathbf{c m}^{2}\right)\end{array}$ & $\begin{array}{c}\text { Kuat Tekan } \\
\text { Rata-Rata } \\
\left(\mathbf{k g} / \mathbf{c m}^{2}\right)\end{array}$ \\
\hline \multicolumn{1}{c}{ Beton Normal } & 2 & 8045 & 58270 & 264 & \\
& 3 & 7795 & 61620 & 279 & 276,6 \\
0,25\% abu kertas, 0\% & 1 & 7815 & 82630 & 374 & \\
serbuk cangkang lokan, & 2 & 8200 & 78060 & 354 & 362,6 \\
0,7\% additive & 3 & 7930 & 79350 & 360 & \\
& & & & & \\
0,25\% abu kertas, 10\% & 1 & 8075 & 86330 & 291 & 365,3 \\
serbuk cangkang lokan, & 2 & 7985 & 77100 & 349 & \\
0,7\% additive & 3 & 8200 & 78550 & 356 & \\
& & & & & \\
0,25\% abu kertas, 20\% & 1 & 7999 & 66770 & 296,7 & \\
serbuk cangkang lokan, & 2 & 7863 & 68930 & 306,3 & \\
0,7\% additive & 3 & 7843 & 67180 & 298,6 & \\
& & & & & \\
& 1 & 7889 & 56890 & 252,8 & \\
0,25\% abu kertas, 30\% & 2 & 7800 & 57050 & 253,5 & \\
serbuk cangkang lokan, & 3 & 7790 & 54940 & 244,2 & \\
0,7\% additive & & & & & \\
\hline
\end{tabular}




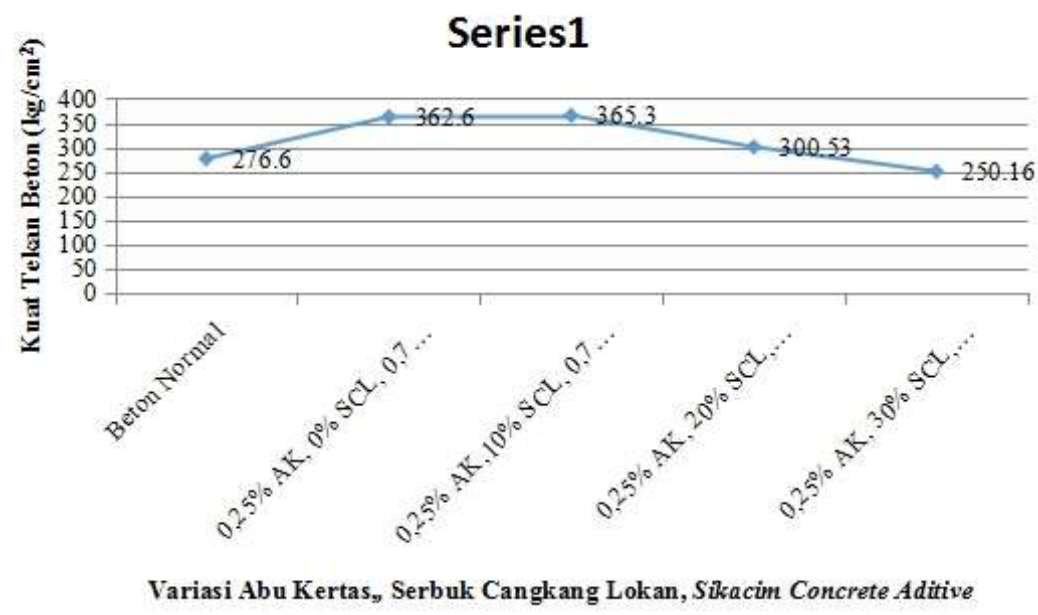

Gambar 5. Grafik Hubungan Variasi Abu Kertas, Serbuk Cangkang Lokan, Sikacim Concrete Additive dan Kuat Tekan Beton

Berdasarkan hasil pengujian kuat tekan beton umur 28 hari didapatkan kuat tekan beton untuk beton normal adalah sebesar $276,6 \mathrm{~kg} / \mathrm{cm}^{2}$. Sedangkan nilai kuat tekan beton untuk penggunaan $0,25 \%$ abu kertas, $0 \%$ serbuk cangkang lokan dan $0,7 \%$ additive adalah sebesar $362,6 \mathrm{~kg} / \mathrm{cm}^{2}$, untuk penggunaan $0,25 \%$ abu kertas, $10 \%$ serbuk cangkang lokan, dan $0,7 \%$ additive adalah sebesar $365,3 \mathrm{~kg} / \mathrm{cm}^{2}$, untuk penggunaan $0,25 \%$ abu kertas, $20 \%$ serbuk cangkang lokan, dan $0,7 \%$ additive adalah sebesar $300,53 \mathrm{~kg} / \mathrm{cm}^{2}$, untuk penggunaan $0,25 \%$ abu kertas, $30 \%$ serbuk cangkang lokan, dan $0,7 \%$ additive adalah sebesar $250,16 \mathrm{~kg} / \mathrm{cm}^{2}$.

Pada penggunaan $0,25 \%$ abu kertas, $0 \%$ serbuk cangkang lokan, dan $0,7 \%$ additive, terjadi peningkatan kuat tekan beton sebesar $31 \%$ dari beton normal, penggunaan $0,25 \%$ abu kertas, $10 \%$ serbuk cangkang lokan, dan $0,7 \%$ additive terjadi peningkatan kuat tekan beton sebesar $32,1 \%$ dari beton normal, penggunaan $0,25 \%$ abu kertas, $20 \%$ serbuk cangkang lokan, dan 0,7\% additive terjadi peningkatan kuat tekan beton sebesar $8,65 \%$ dari beton normal, dan penggunaan $0,25 \%$ abu kertas, $30 \%$ s e rbuk cangkang lokan, dan $0,7 \%$ additive terjadi penurunan kuat tekan beton sebesar $9,56 \%$ dari beton normal.

Pada penggunaan abu kertas dan additive sebagai bahan tambah campuran beton, dengan serbuk cangkang lokan sebagai pengganti pasir, diperoleh kuat tekan tertinggi pada penggunaan $0,25 \%$ abu kertas, $10 \%$ serbuk cangkang lokan, dan $0,7 \%$ additive. Penggunaan serbuk cangkang lokan sampai $30 \%$ sebagai pengganti pasir dapat mencapai kuat tekan beton normal. Hal ini membuktikan bahwa abu kertas dapat bekerja dengan baik untuk mengisi ronga-rongga dalam beton, dan cangkang lokan dapat digunakan sebagai pengganti sebagian agregat halus untuk campuran beton normal.

\section{Penutup}

Berdasarkan hasil pengujian kuat tekan beton pada umur 28 hari, penggunaan serbuk cangkang lokan sampai 30\% sebagai pengganti pasir, dengan penambahan abu kertas $0,25 \%$ dari berat semen, dan zat additive jenis sikacim concrete additive 0,7\% dari volume air dapat mencapai kuat tekan beton normal. Kuat tekan tertinggi diperoleh pada penggunaan $0,25 \%$ abu kertas, $10 \%$ serbuk cangkang lokan, dan $0,7 \%$ additive, yaitu sebesar $365,3 \mathrm{~kg} / \mathrm{cm}^{2}$. 


\section{Daftar Pustaka}

Anonim (1990), SNI-T-15-1990-03, "Tentang Tata Cara Rencana Pembuatan Campuran BetonNormal". Jakarta: Departemen Pekerjaan Umum.

Anonim (1990), SNI 03-1974-1990, “Metode Pengujian Kuat Tekan Beton”, Jakarta: Departemen Pekerjaan Umum.

Erfina, E., (2009), "Pemanfaatan KalsiumOksida (CaO) Cangkang Kerang Jenis Remis dan Lokan Sebagai Bahan Pengganti Sebagian Semen Pada Beton", Jurnal, Fakultas MIPA Universitas Bengkulu: Bengkulu.

https://www.slideshare.net/ihsanmail/bahan-aditif-pada-beton, PT. Sika Indonesia.

Jamal, M., Widiastuti, M., Anugrah, A. T. (2017), Prosiding Seminar Nasional Teknologi IV, "Pengaruh Penggunaan Sikacim Concrete Additive Terhadap Kuat Tekan Beton Dengan Menggunakan Agregat Kasar Bengalon Dan Agregat Halus Pasir Mahakam", Samarinda.

Mulyati (2014), "Pengaruh Penggunaan Serbuk Cangkang Lokan Sebagai Pengganti Agregat Halus Terhadap Kuat Tekan Beton Normal”, Jurnal Teknik Sipil ITP Vol.1 No.1: Padang

Mulyati, Arafan B. F (2019), "Pengaruh Penambahan Abu Kertas Dan Sikacim Concrete Addictive Terhadap Kuat Tekan Beton normal", Prosiding Seminar Nasional Strategi Pengembangan Infrastruktur ke-4, ITP: Padang.

Norman, Juis W U., (2009), "Alternatif Penggunaan Limbah Pabrik Kertas Sebagai Pengganti Semen (CemenTitous) Dalam Pembuatan Beton" Universitas Muhammadiyah: Surakarta.

Nugraha, (2007).“Teknologi Beton Dari Material ,Pembuatan,ke Beto Kinerja Tinggi", Andi Offset: Yogyakarta.

Wahju, J., (2004), "Ilmu Nutrisi” Keluarga Mahasiswa Teknik Sipil dan Lingkungan, Universitas Gadjah Mada. URL: https://id.wikipedia.org/wiki/Kerang.

Wahyuni, A, S., (2013), "Pengaruh Penambahan Serat Bambu Dan Penggantian 10\% Agregat Halus Dengan Abu Sekam Padi Dan Abu Cangkang Lokan Terhadap Kuat Tarik Beton”, Jurnal Teknik Sipil Inersia. 